\title{
Rethinking Education In Botswana: A Need To Overhaul The Botswana Education System
}

Veronica Margaret Makwinja, Botho University, Botswana

\begin{abstract}
Botswana through its two educational reform philosophies of 1977 and 1994 envisioned a developing education system that is on par with international standards. According to Tabulawa (2009), the education system was developed to produce critical thinkers, problem solvers, and innovative learners. The system was designed to provide opportunities for all students by providing access to all, improve the standards of education, emancipate Batswana from illiteracy, and develop their capabilities to create a social transformation in their lives. Education was to be a vehicle for continuous positive change that would ultimately enable people to build a better world. However, the system is wanting since most students drop out of school, fail the national examinations, or are unemployable graduates.
\end{abstract}

Research shows that the standard and quality of education is deteriorating as evidenced by high rates of failure at primary and secondary schools. This paper established the reasons for deteriorating standards and failure of students; and whether this was a result of the difficulty, the country finds itself in attempting to re-think and change its educational system to improve the standards or any other factors. This paper reviewed the obstacles leading to high failure rate in one primary school and the need to overhaul, rethink, reform and transform the country's education system.

This study was carried out at the Ministry of Education and Skills Development, which is presently divided into two sub departments; the Ministry of Basic Education and Tertiary Education, Research, Science and Technology and one (1) primary school in Gaborone through the use of qualitative method.

Keywords: Reform; Rethinking; Transforming; Change; Paradigm Shift

\section{INTRODUCTION}

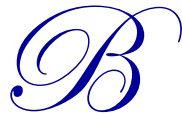

otswana's leaders have always been visionaries since the country's first president, Sir Seretse Khama and some of the leaders visualized an inclusive form of education different from what was perpetuated by the former missionary and colonial leaders. The leaders envisioned an education system that provided access to all and supported social harmony after the realization that the Botswana community was isolated according to different ethnic groups. The attempt was to unite the nation and maintain peaceful co-existence. Observers can see this through the fact that Batswana can joke about each other's origin or ethnicity without causing any blood shed or animosity. The thinking behind this principle led to the formulation of the National Policy on Education (NPE) of 1977 that addressed on the four (4) national principles of democracy, development, self-reliance and unity popularly known as education for Kagisano (which literally means social harmony).

It may be inferred that the education policy attained its name from the various ethnic groups found in the country who have co-existed in harmony despite their cultural diversity. Botswana is a harmonious country that allows every citizen to live anywhere they choose without any interference on their freedom. This peaceful co-existence was perpetuated throughout the education system which also inspired the Batswana to move from an agro-based to an industrial based economy (RNPE,1994), meaning that the education system was to incorporate curriculum that provided skills for the 
development of the country, instead of emphasizing on the 3 Rs (arithmetic, reading and writing) the curriculum had to incorporate more practical subjects such as agriculture, art and music.

However, the teacher-centered approach remained the primary method to an extent that very limited practical work was done by the students. The teacher continued to be the bearer of the knowledge while the students remain the recipient. The examination oriented curriculum further maintained the status quo by leading teachers to teach to the test. This discouraged critical, analytical and hands on experience; continuing the culture of memorizing amongst the students for regurgitation during the examinations. The study reviewed the reasons for continuous poor performance in schools despite the efforts made through educational policies that provided innovations to improve learning and teaching in schools. The performance of students in schools in Botswana plummeted year after year despite the various innovations embedded in the educational policies. The study unraveled various reasons for high failure rates in one Botswana primary school.

The main research question established why, despite all the efforts and innovation made and incorporated into the education system by the government and Ministry of Education and Skills Development to improve the quality of education in Botswana, performance in schools was still lacking improvement.

\section{Significance of the Study}

The researcher believes that the study will assist education policy makers, The Ministry of Education and Skills Development, teachers, parents, and other interested education stakeholders by developing better strategies of educating children for the future and betterment of the society and reduce dropout rates, attrition, and failure rate in schools. The researcher will further suggest an alternative way of developing a more inclusive curriculum as opposed to what is the present "one-size fits- all" curriculum, to enable curriculum developers to adapt some of the proposals.

\section{LITERATURE REVIEW}

The first National Policy on Education (NPE) of 1977 was a reaction by Botswana leaders to move away from the British colonization model of learning to a more inclusive system when education was for the elite. The second policy known as the Revised National Policy on Education (RNPE) was explicit in its endeavor to prepare Batswana for the transition from a traditional agro-based economy to the industrial economy. It further addresses issues of access, equity, and the improvement of the quality of education (RNPE, 1994). However, a lot still needs to be done to provide quality education for Batswana children. Other reforms to transform the Botswana society into, "An Educated, Informed Nation Education By the year 2016" were from Vision 2016 (Vision 2016, p.7). This envisioned a country with a system of high quality education that would enable individuals meet the changing needs of the country and the world. The country would transform into the information age to keep pace with the rest of the world (Vision, 2016).

This Pillar of vision 2016 has not been attained due to various challenges facing the education system to date. Not all Batswana are educated. There are still children from marginalized communities who fail to complete their school program. There are street children who have no alternative form of education; high rates of unemployment of graduates from tertiary education due to failure to meet industry requirements.

\section{Other Innovations}

Botswana capitalized on the Millennium Goal 2 that advocated achieving universal primary education and its target was to ensure that by 2015 children everywhere, boys and girls alike would be able to complete a full course of primary schooling (Vision 2016 and Millennium Development Goals Indicators Report, 2014).

Since 2015, the government set a 5 year Education and Training Sector Strategic Plan (ETSSP: 2015-2020) to guide decision makers and planners to reform and improve education after identifying several challenges within the education system. Its intention is to match qualifications and labour market requirements in order to align education outputs with future employment needs (ETSSP, 2015-2020). It addresses issues of quality, relevance, access, equity, and accountability across the entire sector, from pre-primary school to tertiary level (ETSSP, 2015-2020). This is in line with The Education for All (EFA) movement, which committed to providing quality basic education for all 
children, youth, and adults (Botswana Education for All, 2015 National Review). However, the ETSSP did not introduce any innovations because the ideas proposed were a replica of the previous policies. It repeated what the RNPE advocated and its deadline was 2015. This is a major concern since there has not been any other innovative policies planned after 2015 .

\section{Innovation in the Curriculum}

\section{Pre-School Education}

Pre-primary education was not a priority in the first national policy. However, Botswana views early childhood as an important component of the education system. The benefit of pre-primary education cannot be over-emphasized because children develop cognitively and socially (Statistics Botswana, 2013). The government has further expressed a commitment to address the rights of children from an integrated approach to early childhood development and education. There has been an implementation of the standard one orientation program, which runs for 6 weeks, and a reception class program for a year. The reception class started in 2014 and is expected to end in 2018. The new Education Training Sector Strategic Plan (ETSSP, 2015) stresses the importance of early childhood education, professional and pedagogical renewal.

\section{Primary Education}

The RNPE admitted that the poor quality of education is due to inadequate facilities and poor teacher's accommodation (RNPE, 1993). News leaked to one newspaper in Botswana quoted the then Minister of Education and Skills Development, Dr. Pelonomi Johnson acknowledging the failure of the government to provide quality education, "We failed you", reads the headline (Mmegi) ever, the RNPE had vowed to provide classrooms in each school. Other facilities such as fully equipped science room and equipment, health activities room, sports field were to be provided. Despite all the attempts to provide learning facilities classrooms in Botswana still, carry more than the capacity although it was recommended that a class must hold between 30-35 students. For example, it is not uncommon to find a primary classroom filled with $40-45$ students.

\section{Equipment/Supplies}

Schools were to be equipped with computers/typewriters, reprographic equipment, library books etc. However, not all schools have these materials and most primary schools when teachers' need to make copies they go either to the nearest education center or another school for assistance. According to Lauglo, Akyeampong, Mwiria, \& Weeks (2003), although huge investment has been made in new educational technologies, the results of access and usage have been poor, a common trend in Botswana schools.

\section{Curriculum, Assessment, and Examination}

Recommendation 17 of RNPE 1994 (para.4.7.22) dealt with the primary school curriculum, assessment and examinations which advocated an integration of new subjects that were separated into core and optional subjects. Subjects such as art, craft, home economics, music, and physical education were to be included in the primary syllabus. It was further recommended that there should be periodic monitoring and evaluation strategies in place to meet the objectives.

The challenge in primary schools is that practical subjects such as arts, crafts, and music are not given the same priority as the core basic academic subjects. They are not examined and therefore are scheduled during the end of the day when the students are exhausted.

Recommendation 36 advocated a move towards Criterion Referenced Testing to measure all aspects of students' ability. Students sit for the standard 4 Attainment Test that is a mechanism to assess if students have attained the set objectives. When a child attains a percentage below 50, they are made to repeat standard 4 . If more than 5 students fail, only five are allowed to repeat by the Ministry of Education and Skills Development (MOESD). However, those made to repeat are the once the teachers feel have a potential to improve their academic prowess. Those who the 
teachers find it difficult to attain the objectives are left to progress through the education system despite observations made that these children have learning styles that are not catered for in the curriculum. The World Bank Working Paper (2008) mentions the lack of alignment between curriculum and assessment. Teachers in schools in Botswana have complained over time of concepts that are sometimes examined without having been covered in the curriculum. Language policy

Recommendation 18 (para.4.7.3) of the RNPE of 1994 purports that English is the medium of instruction from standard 4 to 7. According to Arthur (1998), the level of proficiency in English is very low leading to code switching to enable the children to understand better. The recommendation seeks to improve the teachers' qualifications, competencies, and strengthen the roles of the school head as the instructional leader. Most teachers have been upgraded to higher qualifications such as degrees in primary education and educational management. However, it is questionable if this has improved the teachers' English proficiency or ability to use English as a medium of instruction.

\section{SECONDARY EDUCATION}

The RNPE (1994) set the policy's goal for the junior certificate curriculum (grades 8-10) was develop children's proficiency in the use of Setswana and English language for effective communication. The curriculum was to enable the students to understand their society, culture and be patriotic. The students were to learn how to utilize the computer, appreciate technology, understand scientific concepts. They would be taught about the business world and become analytical, problem solving, and critical thinkers.

\section{Curriculum}

Recommendation 32 (para. 5.5.13) indicated that the students would take a maximum of 10 subjects. The curriculum included six core subjects (English, Setswana, social studies, mathematics, integrated science, design and technology, and a basic computer awareness course). The students selected a maximum of four optional subjects from the following list; home economics, agriculture, commerce, principles of accounts/bookkeeping and office skills. Other choices could be made from development studies, religious and moral education, third language (French, other local languages), music and physical education.

\section{Pre-Vocational Preparation}

It was suggested that the Careers Guidance teacher was to coordinate and implement the pre-vocational program. Teachers' skills and competencies in career guidance were to be enriched and students were exposed to commerce and industry.

The commission recommended a mixed ability in-service training policy for teachers to meet the wide range of ability in secondary schools (Recommendation 35) (RNPE, 1994). This mixed ability and remedial teaching strategies were to be included in the teachers' pre-service programs. The Ministry of Education was expected to formulate to ensure that slow learners are assisted by the teachers.

\section{Boarding Facilities}

The recommendation was that a boarding policy be set up to enable students living outside a 5 kilometers radius should be provided with boarding accommodation. However, most children in remote areas still walk long distances to school.

\section{TRANSFORMATION OF THE EDUCATIONAL SYSTEM}

The Botswana government through the Ministry of Education and Skills Development translated and adapted the Millennium Development Goals through sustainable universal access to all equally for both girls and boys (Botswana Millennium Development Goals, 2010). According to the same report, key dimensions of educational performance, e.g., enrolment, adult literacy, school infrastructure, basic equipment, supply of teaching materials and teacher qualifications have improved markedly since independence. The Botswana Millennium Development Goals of 2010 
continues to report that the Net Enrolment Ratio (NER) of both the 6-12 and 7-13 NERs declined after 2005 (Botswana Millennium Development Goals, 2010).

It is believed that dropout rates have decreased in primary schools. However, in remote rural areas the way of life of the communities exacerbate the dropout rate since children may leave school to follow their parents during seasonal harvesting and planting seasons. Some may be affected by migratory patterns of semi-nomadic communities, language barriers and economic pressures on poor families, especially the boys. At secondary school level, girls drop out more due to teenage pregnancy.

Another issue is the high maintenance of schools that are not fully utilized such as in small settlements driving up the per capita cost of education. The schools in these areas are meant for the Basarwa/San/Bushmen and other communities in remote areas are costly and logistically challenging. A lot of children in many areas of the country including the remote areas walk long distance to school and teachers are resistant to work in these regions. Some children from poor families or disadvantaged minorities work as farm labourers, an issue that defeats the purpose of the Children's Act of 1990.

\section{Quality of Education}

The quality of education is still questionable though a lot of money has been spent on it. In the 2016 budget year, 10.64 BWP or $28.8 \%$ of the total national budget goes into education (Budget Speech, 2016). Despite the investment on education, several children either drop out of school before they complete their term of study or perform badly in the national/international examinations. However, many teachers have been sent for further studies to improve their teaching strategies.

The school infrastructure has improved to a certain level but a lot still needs to be done. Many schools have adequate classroom space and furniture but very limited technology and internet services.

\section{Inclusive Education Policy}

The Ministry of Education and Skills Development will implement the objective of the RNPE (1994) and provide inclusive education and special education for those in needs. Child friendly schools can enhance chances of attaining an inclusive education system. The department of Technical \& Vocational and Education Training TVET has an equal opportunities policy that will ensure that a certain percentage ( $15 \%$ quota for admission of students) is reserved for students from disadvantaged backgrounds.

The intention of the RNPE (1994) was to ensure that schools are equipped with the appropriate tools for learning but unfortunately this did not reduce the high failure rate. According to the Botswana Examination Council (BEC); the section of the Ministry of Education that releases both the national and international results, in 2014 a total 37, 384 students who took the examinations.

Botswana students sit for the General Certificate of Secondary Education Examination (BGCSE) and the International General Certificate in Secondary Education (IGCSE), which is commonly pursued in privately owned, schools commonly known as English medium schools in Botswana. A large number of the students, 25186 were enrolled in government or public school while 2936 were in full time attendance at privately owned schools. 9266 students were enrolled as private candidates in a long distance learning institution called the Botswana College of Distance and Open Learning (BOCODOL) while some had either failed in the previous years and registered as what the country term "back-to-school candidates".

Of the total students who sat the 2014 examination, only $25.75 \%$ (5 796) obtained Grade C or better. The rest of the candidates obtained Grade D or below. The BGCSE results have been declining since 2006 even though the two thirds of the national budget is allocated to the education sector. What is disheartening is that the rural youths are more prone to failure and their future is uncertain from an early age leading to involvement in crime, drug and alcohol abuse coupled with negative health effects that tap further into the country's limited resources. Manpower development is grossly affected by this failure trend leading to high levels of economic inequality between rural and urban areas. For 
a long time, Batswana have believed that, good education ensures a good job although recently children have completed their studies but remain unemployed. For the poor this increases the gap between them and the rich.

\section{METHODOLOGY}

The Researcher used the qualitative method to collect data. Five (5) teachers were interviewed and one Ministry of Education and Skills Development (MOESD) Inspector was interviewed. The sample was based in Gaborone, the capital city of Botswana with a population of 200000 people according to the 2011 population census. The primary school chosen is in an area that began as a squatter camp and is one of the low-income areas in the city. Most of the people living in this area are unemployed and some make a living from selling traditional or illegal beer. There are high rates of crime.

In analysis the data was organized thematically, based on the innovations stipulated by the policies reviewed and the responses from the respondents/participants.

The researcher was granted permission by the MOESD and Regional Education Officers and School head to conduct the study. The participants were granted anonymity by not using their names in reporting the findings.

\section{FINDINGS}

\section{Rethinking and Overhauling the System}

When the Principal Education Officer (Inspectorate) (PEO) was asked if he thought the education system should be re-though and overhauled, he responded thus;

"Of course as it is education is against what the industry requires". He felt that most of the country's graduates were not internationally competitive despite the fact that some might have studied in certain vocations. He compared them to Zimbabwean graduates who were able to perform various activities such as building a house to completion without requiring extra help. He stated that Botswana's problem was lack of appreciation for" blue collar" jobs that tend to employ foreigners. He lamented about the high rate of unemployment that affected economic growth.

One teacher mentioned an important issue that the Botswana government failed to recognize primary schools which are the foundation of education. Heads of Departments in primary schools were teaching and handling administrative duties at the same time. They supervised other teachers and the support staff including completing appraisals for them on behalf of the Local Government Ministry, which supervises support staff.

Teacher: "It's a contradiction in terms.... Supervision of support staff is done by MOESD employees but the results are sent to the Ministry of Local government".

\section{Teachers' Welfare}

Primary school teachers complained about their salaries and that their secondary school counterparts with equivalent qualifications were paid more than them.

\section{Innovations from Policies}

The PEO and the five teachers who were in a focus group indicated that innovations detailed in policies had not been implemented as expected. One teacher further mentioned that policies were never monitored. The PEO stated that if the 1994 policy was implemented, the education system would be highly developed. He lamented about the lack of implementation capacity and most policies were not used. The Researcher questioned why new policies were drawn while the existing ones had not been fully implemented, and the PEO alleged that most of the decisions made were politically driven. He further commented on the latest policy known as ETSSP that it was merely the 1994 RNPE called by a different name, sentiments shared by the Researcher in the argumentative literature review. 
"Had we implemented RNPE we didn't need ETSSP".

Another issue of concern in implementation of policies was the "quick" change in leadership where ministry personnel at high levels are re-shuffled and posted to different ministries. Each new leader had their own ideas and preferences and this delayed implementation.

The teachers explained that there were always innovations introduced in schools and these would be shelved away before they are evaluated to check their effectiveness, 'they benchmark from all over".

When quizzed about the latest policy [ETSSP] the teachers had no clue about the existence of such a policy. One respondent indicated that no research was done on innovations introduced and mentioned the latest innovation that was introduced known as "literacy reading" that was piloted by the Canadians. Since it worked for the Canadians it was taken for granted that, it would work in Botswana. He further indicated that educators did not want to invest time to understand why performance was poor in schools.

One member of the focus group referred to the RNPE that advocated for less than 40 students per class, which was never implemented. Today's classes range between $40-45$ students.

The teachers referred to their teaching of several students when they had specialized in one or two subjects. He mentioned that there was no teaching in schools but the focus was on producing the largest number of passes, hence teaching for the examinations.

\section{Performance Management System-a Policy}

One of the teachers expressed his dislike for the policy since it was used to threaten teachers. He indicated that the policy was adopted with the right focus but was at the moment not measuring what it was meant to. It had objectives for the beginning, mid and end of the year but unfortunately the MOESD would derail its intentions by introducing its own agenda and issues. The students 'performance took precedence over actual learning and therefore teachers were forced to drill the students to pass in order to meet the requirements of the ministry.

One teacher emphasized that a tool used needed to be clear about its purpose. He indicated that every education personnel and stakeholder were not sure of what is to be done with the PMS system and there was need to contextual the present tool used in schools.

\section{Curriculum}

The PEO confessed that he was not well versed with the primary school curriculum since he was a secondary school teacher. However, he indicated that the whole curriculum needed overhauling, especially in subject areas. He failed to understand why students had to start learning pure physics, biology, and chemistry at high levels instead of starting at lower levels.

He further echoed his concerns about the teaching of History and Social Studies; that the 2 subjects were overtaken by events. His wish was for students to learn contemporary subjects such as International Relations and Protocol that would expose the students to reality and job market skills.

The teachers commented on the how the new curriculum that it did not match with the time allocated for teaching the subjects. For example, mathematics was allocated 4 hours per week. One teacher questioned the methods used to design the curriculum. He further explained that for teaching standard 5 mathematics, the teacher required 14-15 months to complete the syllabus. Therefore what happened was that teachers drilled the students to meet the objectives.

One teacher complained that the Agricultural Science syllabus was developed by secondary school teachers.

Teacher: I think it's just not right that we have people... those teaching and deal with daily curriculum must be the ones dealing with the curriculum unless there's a justifiable reason why they should be there". 
The same teachers alleged that content that was supposed to be taught at grade level 8 was transferred into the primary school syllabus. He felt the secondary school teachers made their work easier than struggle to teach new students.

Teacher: I want to give a typical example of the workload brought to primary schools... topics taught in primary repeated in JC and the teachers the teachers are having it easy".

When the teachers were cross-examined about the importance of early childhood, they mentioned that in areas where the parents could afford early childhood, the children performed much better. In their case their students did not have, that opportunity and therefore the teachers had to put in more effort to assist the children comprehends what is taught.

\section{Specialization in Subjects}

One teacher wondered why primary school teachers specialized in one or two subjects but were expected to teach all the 9 subjects.

\section{Administration of Schools}

He complained about poor school administrators for poor performance in schools. He however stated that schools were staffed with well-trained and effective teachers but unfortunately, administrators in schools were not trained leaders, but instead were also teachers who performed well in certain subjects.

\section{"We need to transform them to handle management".}

The PEO stated that they carried inspection in school and produced reports. Some administrators found it difficult to interpret the reports or implement them.

One teacher stated that in primary schools the number of subjects had increased from 5 to 9 . One of the teachers commented on the testing methods that some subjects, such as Agriculture's examination were prepared by secondary school teachers who developed questions that required critical analysis when in actual fact standard 7 students are used to multiple-choice tests, thus testing knowledge that was never taught. They additionally argued that examiners were fond of asking about current affairs or events that happen in a particular year; questions which are not from the set objectives.

\section{Resources}

One teacher compared primary to secondary that resources secondary schools took for granted primary schools operated without such as the internet, transportation, printing facilities. The teachers felt that the MOESD supported secondary schools more than primary schools. One teacher alleged that the MOESD always reported providing schools with computers but these would be used due to lack of skills. There are no trained technicians to operate the computers. Only teachers who have an interest in using technology have access to the computers.

Teacher: "Schools are taken as a dumping site and how do you expect a child to use a computer that was freezing when you used it?"

\section{School Environment}

The PEO indicated that the school environment did not meet the needs of the $21^{\text {st }}$ century learner. He alluded to the lack of technology in the classroom and schools not allowing students to bring their smart phones to school to use them for research. He stated that a school could have 15 computers only accessed by the teachers, 'in terms of technology, we are too far".

The teachers were more concerned about their welfare and emphasized that because their needs were not catered for; this affected their performance such that they failed to put effort in their work hence high rates of poor performance. 
The teachers worked in a non-secure environment with people having easy access to the school such that there were instances where people jumped over the fence brandishing knives. Most teachers refused to teach in this particular part of the city.

\section{Classroom Environment}

He reviewed the classroom environment according to the teachers' ability to control the students. He indicated that the environment differed from one teacher to the other with some teachers managing the students well. He showed concern about the lack of motivation among teachers who took the profession because they had no alternative. The teachers alluded to the fact that there were no books for the students to use; in that particular school 150 students shared 20 social studies books.

\section{Feeding System}

The Researcher needed to establish the feeding system in schools and the PEO elaborated that primary schools straddled between 2 ministries; that of education and local government. This was confirmed by the teachers. The Local government ministry failed to provide nutritious or adequate food to the students. Nonetheless, secondary schools were given funds to purchase food for the students and could vary the food they fed the students.

Teacher: "We are used to those frustrations, we roll with the ball".

The teachers interviewed taught in a low-income area and if they failed to feed the children they knew the children would stay hungry. The teachers explained that there were instances where they felt guilty for releasing children earlier than usual to go home because they knew the children would not have anything to eat at home.

\section{Inclusivity}

The PEO confessed that Botswana public schools traditionally and at the time of the study were not inclusive. Challenged students and those living with disabilities were incorporated in the normal classroom but did not receive adequate assistance due to deficiency in special education skills by the teachers. At the time of the study, the ministry of education was in the process of implementing programmes that would make the schools more inclusive.

He mentioned 2 special education units in one (1) primary school and the Japanese embassy had pledged to build another one at a junior secondary school. One senior school admitted challenged students, teachers with disabilities, and those affected by HIV and AIDS to enable the teachers to access medical facilities within the city. Due to alcohol and drug abuse by parents, there were mentally challenged children who were included in normal classes in the school, without special care provided. The teachers handled these children through trial and error and the teachers were only concerned about those students who would pass the examinations at the end of the year, hence neglecting the challenged students. Some of the children also drank and smoked.

The teachers claimed there were schools with special education units and children were tested differently from the socalled normal students. Those who needed transcribers during the examinations were provided for and their failure rate was low.

\section{Parental Involvement}

The PEO reported that parental involvement differed from one school to the other. In Gaborone, more parents were literate and professionals and attended school activities in large numbers and followed up on their children's performance.

In the low income residential area, parental involvement and control was very poor. The children suffered negligence; some spent too much time in the streets while others were vendors after school. The politicians moved around bars and entertainment spots chasing the children away and try to discourage parents allowing children to visit public 
entertainment areas. Most children in primary schools lacked basic needs such as shoes and decent school uniforms. However, the same negligent parents would prefer to take care of their secondary school children, but were unable to.

Despite these challenges, the teachers felt since they tried to motivate the children, their performance was improving. For example, they gave motivational talks and counseling and were assisted by the political leaders in their area. The teachers had a lot to do in this area to get better results including adapting to the challenging environment. Another encouraging thing was that a few fathers were present in the school during certain events and coming in to collect their children's report cards, a thing unheard of in the past.

\section{Self-Directed Learning}

The PEO reported that students pursuing science subjects were able to learn on their own but the majority was challenged. He referred to the country's automatic promotion system where students moved to a higher class despite their performance had an impact on the quality of education and performance. Furthering his point, he stated that some students were not cut out for school. They had no interest or self-drive because they had failed during the course of their programs but due to automatic promotion, we made to stay in school. This caliber of students had no dive to learn.

However, it was recounted that most of the students were well behaved with a small number that engaged in the use of marijuana, cocaine, and making profit out of it. These could not perform well at school.

\section{Counseling Facilities}

The PEO informed the Researcher that counseling facilities were not available in school and a few teachers both in primary and secondary schools were trained in Guidance and Counseling and were not professionals. "We need people who have done psychology".

The teachers felt that counseling of students was difficult because of their dual role but in that, particular school teachers spent time counseling. They counselled the students face-to- face or as groups, including their parents and most of the challenges children faced emanated from home. He made referrals to the social welfare department.

Teacher: "There are extreme things happening such as improper sexual harassment. In 2015 a standard 6 pupil dropped out impregnated by an elderly man in the society".

Some teachers indicated that some children found it difficult to discuss their problems with their teachers. The teachers would observe certain behavior when they talked about life skills or sexual matters and would use the opportunity to discuss with the children the effects of indulging in pre-mature sex, etc. One of the issues the children shared with the teachers was the absence of the fathers in their lives and were concerned about the separation from their fathers. They alleged that during and after divorce, parents used them to fight against each other.

\section{OBSERVATIONS AND DISCUSSIONS}

The findings from the study confirm the researcher's hypothesis of the need to overhaul the country's education system. The policies on education (RNPE 1994 and ETSSP 2015-2020), Vision 2016 and various innovations have comprehensive recommendations that have not been implemented either due to lack of capacity or fragmentation of the education departments following different agendas. There are no new ideas in the latest ETSSP, which is a duplicate of the 1994 RNPE.

Though several schools have been constructed in the country the learning and teaching environment is non-conducive for a $21^{\text {st }}$ century learner. The four-walled classroom, the seating arrangement, use of old chalkboard in the school studied is an indication of poor planning and lack of proper policies to enable access for all. Children are still crowded in small spaces with an intake of between 40-45 students. Children learn in classrooms with broken windows, doors and chairs and some share chairs. It is therefore inherent that the Botswana government to totally transform the education system and provide all the basic need for learning. 
It is important that the curriculum is reviewed and pre-school or early childhood education be planned for properly and made universal to all children. The curriculum is difficult for the teachers to interpret and there are too many topics to be covered. The children's learning abilities are questionable due to several problems such as poor reading culture of families in Botswana, poor exposure to learning opportunities, poverty and other challenges to mention a few.

The environment under which the new pre-primary/early childhood learning program was established is below standard. The young children learn in a non-conducive environment, which is no way closer to preparing children for the foundational education. Most classrooms used are poorly resourced with mostly paper, calk, the chalkboard and teachers as the provider of knowledge. There are no computers for the children to explore and learn through. The young 5-6 year olds sit on high chairs and desks meant for the standard seven pupils. There are no materials or equipment used to expose the children to learning in the $21^{\text {st }}$ century.

It is essential for the government to appreciate the teachers 'efforts and provide them with the proper training, counseling and motivation especially those working in challenging environments similar to the one the study was carried out at. Teachers in Botswana are very dissatisfied about their working conditions and it seems there is no proper handling of this important issue. If this trend continues, the standard of education and performance of the children in schools will continue to plummet from year to year.

School administrators must be trained to enable them to coordinate the school activities with expertise and not trial and error as it is common in most schools.

Parental involvement is wanting. It is incumbent on Botswana schools to hold training sessions of how parents could assist children in their learning and find ways to feed them before sending them to school. The government is providing poor families with food packages and parents must learn to use them for the right purpose unlike the reports schools receive of parents selling the food stuff at time in exchange of alcohol or drugs.

The findings indicated lack of self-directed learning among the students, which calls for supervision between the schools and homes; a tradition that Botswana practiced in the past. This could be resuscitated through continuous counselling of both the children and parents. There is a development in the country of young parents who require parenting skills and schools could be enhanced to provide this on case-by-case basis. When counseling students the school could make arrangements for counseling session for the parents so that the child does not return to the same environment they previously experience.

\section{CONCLUSION}

The researcher advocates a more transformations system of teaching Batswana children to enable them to perform to the expected standards through a thorough evaluation and analysis of the learning barriers faced by communities in Botswana. There are great inequalities in the Botswana society such as poverty, lack of proper care of the orphans, lack of learning facilities in almost all schools, lack of access to basic needs and many others which affect the children's learning. These challenges require commitment of all stakeholders involved with educating children to find better ways of directly and properly using working strategies to solve them. They do not require sitting in meetings and setting unattainable goals.

Some communities in the country suffer the above and due to their children are unable to grasp the general concepts that today's curriculum offer in Botswana. This calls for dialogue with communities on the type of education suitable for their children. The generic curriculum could be used as a stepping-stone to incorporate concepts that make sense to those particular communities. For example, Basarwa children perform poorly in the national examinations because concepts dealt with in the curriculum are unfamiliar to them. For example, their books depict pictures of aero planes, rivers, trains, and hills features that the children have never seen. Unfortunately, there are no computers for research let alone electricity. The curriculum needs to be more cultural, and context sensitive, which is still a challenge for the country. 
Vocational education must be encouraged and taught from the early ages; at pre-school or early childhood classes. The former education system advocated the 3Rs more at the expense of vocational skills. Children who excel in vocational education could be allowed to pursue their interest and passion unlike where a child progresses through the education system only when they have passed academic subjects. The government could set up vocational wings in the school where children specialize in various trades that could become their profession in the future. For example, if a child excels in music they should be trained well in music to become a professional musician.

The reason for the above is that the government is the sole employer of graduates from tertiary institutions. Now there are no vacancies left and a large number of graduates are walking the streets unemployed. This is one of the worst unemployment crises in the country with unemployed graduates beginning to express their dissatisfaction and demonstrating against their plight.

Reforming and transforming education is long overdue in Botswana. The Botswana government must review its education system whether it is suitable for a Motswana child whose basic needs are still no met. There is talk internationally about globalization and internationalization of education and one wonders how appropriate this trend is for a country young as Botswana that is unable to globalize within its boundaries, so how it could do so internationally. Education is a human right and all children must access it fully with all the necessary provisions to enable them to succeed in their learning.

\section{AUTHOR BIOGRAPHIES}

Veronica Margaret Makwinja has been an educator in both high schools and tetiary institutions for a period of over 30 years. She holds an ed.d in educational administration from Ohio University, Athens, USA, where she was recognised as the most outstanding student in educational administration in the 2006 in the college of education; and a masters of science in the same from Syracuse University, NY, USA. Her passion as an educator is to contribute to transformation in the Botswana education system that is more inclusive, especially for the marginalised and disadvantaged. She has published some journal articles with internationally renowned and referred journals and continues to pursue research mostly in basic education which prepares the clientele for tertiary institutions. She has published books in social studies, guidance and counselling whch have been used in high schools in Botswana. She currently works for Botho University, a private tertiary institution in botswana as a head of department in the faculty of graduate studies and research.

She believes that if the basic education foundation is weak, higher education in Botswana would never be internationally competitive or produce employable graduates. She is a proud mother of twins and very prayerful.

\section{REFERENCES}

Arthur, J. (1998). Institutional practices and cultural construction of primary school teaching in Botswana. Comparative Education, 34(3), 313-326.

Botswana Education for All 2015 National Review. (2015). Gaborone: UNESCO.

Botswana government (2015). Botswana Education \& Training Sector Strategic Plan (ETSSP 2015-2020). Retrieved from ww.gov.bw/Global/MoE/Acts/MOESD\%20ETSSP-

EDUCATION\%20STRATEGY\%20approved\%20version\%20II.pdf on the 23 August 2016.

Botswana Millennium Development Goals. Status Report (2010). Gaborone: The United Nations in Botswana.

Botswana government (2013). Pre-primary education 2013. Gaborone: Statistics Botswana.

Botswana government (2014). Vision 2016 and Millenium Development Goals Indicators Report. Statistics Botswana.

Lauglo, J., Akyeampong, A. K., Mwiria, K., \& Weeks, S.G. (2003). Vocationalized secondary education revisited, with case studies from Botswana, Ghana and Kenya. Working Group for International Cooperation in Skills Development. Edinburgh: International Labour Organization.

Meeting basic learning needs: A vision for the 1990's background document. World Conference on Education for All Meeting Basic Learning Needs (1990). New York: CEFA.

Ministry of Finance and Development Planning. Budget speech delivered to the National Assembly on by Mr. Kenneth Matambo on February 1, 2016. Retrieved from ww.dailynews.gov.bw/common_up/dailynews/02-02-2016_2016-budgetspeech_1454424971_doc_25870.pdf

Republic of Botswana, (1994). The Revised National Policy on Education April 1994. Gaborone: Government Printer. 
Tabulawa, R.T. (2009). Education reform in Botswana: Reflections on policy contradictions and paradoxes. Retrieved from http://www.ubrisa.ub.bw/bitstream/handle/10311/733/Tabulawa_CE_2009.pdf?sequence=3 on the $23^{\text {rd }}$ August 2016. World Bank Working Paper no. 128. (2008). Curricula, examinations, and assessment in secondary education in sub-Saharan Africa. Washington, D.C: The World Bank. 
NOTES 